\title{
Anticancer chemotherapy in teenagers and young adults: managing long term side effects
}

Cancer is the leading cause of disease related death in teenagers and young adults (TYAs) in Western countries. ${ }^{12}$ In the UK, cancer in TYAs accounts for $9 \%$ and $15 \%$ of all male and female deaths respectively, and its incidence has risen by $19 \%$ since the mid-1990s, leading to 2300 new cases a year between 2011 and 2013. ${ }^{1}$ In Japan it accounted for nearly 7000 deaths between 2000 and 2006 . $^{3}$ TYA cancer survivors are likely to live for many decades but are at risk of late effects of their treatment. This article provides information for generalists on late effects of anticancer chemotherapy (see infographic and supplementary table A) that may affect quality of life. Radiotherapy related effects are not discussed but are summarised elsewhere. ${ }^{4}$

\section{Defining teenagers and young adults}

There is no internationally accepted age definition for TYAs. In the UK, TYA age is 15-24 years, whereas the US National Cancer Institute defines adolescents and young adults as aged 15-39 years. In this review we use the UK definition of 15-24 years.

\section{Types and prognoses of cancer in TYAs}

Table $1 \Downarrow$ lists the most common cancers seen in TYAs. The most common cancers seen in this age group are lymphomas, carcinomas (such as breast, bowel, cervix, and thyroid), and germ cell tumours. Survival rates for these TYA cancers are generally good, with five year survival around $85 \% .{ }^{5}$ Five year survival for Hodgkin's lymphoma and germ cell tumours is more than $90 \%$, but sarcomas such as osteosarcoma (60\% survival) carry worse prognoses. ${ }^{6}$
Chemotherapy plays a major role in the treatment of these cancers, and TYAs are potentially exposed to a wide range of chemotherapy agents, each with distinct late effects. A comprehensive literature review highlighted that these effects are generally different from those seen in younger children and adults, specifically in terms of cardiac toxicity, second malignancies, pulmonary complications, and psychosocial difficulties. $^{7}$ The reasons for this are not fully established, but it is partly because younger patients receive more intensive chemotherapy regimens and usually live longer, and thus have more time to develop late effects. There remain several important unanswered questions about cancer treatment in TYAs, some of which are detailed in box 1 .

\section{What are the late effects of chemotherapy?}

\section{Cardiovascular disease}

Chemotherapy is associated with delayed cardiovascular complications including coronary artery disease, ventricular failure, and hypertension. ${ }^{8}$ A Danish cohort study of more than 43000 TYA cancer survivors found an absolute excess risk of up to 400 extra hospitalisations due to cardiovascular disease per 100000 person-years in survivors compared with the control group. ${ }^{9}$ A similar US study identified a twofold increased risk of cardiovascular disease, which adversely affected survival. ${ }^{10}$ These associations have been confirmed in specific cancer subtypes such as Hodgkin's lymphoma and testicular cancer, ${ }^{11}$ where treatment regimens often contain anthracyclines and cisplatin. 


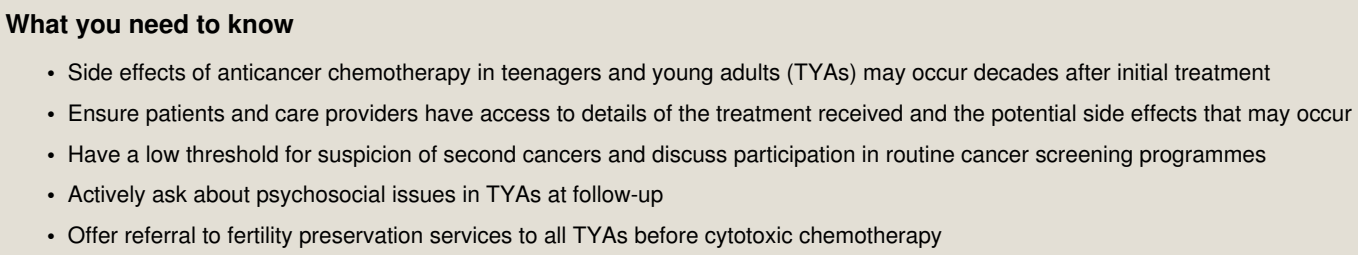

- Side effects of anticancer chemotherapy in teenagers and young adults (TYAs) may occur decades after initial treatment

- Ensure patients and care providers have access to details of the treatment received and the potential side effects that may occur

- Have a low threshold for suspicion of second cancers and discuss participation in routine cancer screening programmes

- Actively ask about psychosocial issues in TYAs at follow-up

- Offer referral to fertility preservation services to all TYAs before cytotoxic chemotherapy

\section{Sources and selection criteria}

This article is an evidence based review of late effects of chemotherapy in teenagers and young adults (TYAs). Our review encompasses studies using all age ranges termed as TYA or adolescents and young adult (AYA). We searched PubMed and the Cochrane databases between 1990 and 2016 using the search terms "teenage and young adult cancer, adolescent and young adult cancer, TYA, AYA, late effects, chemotherapy, survivorship" to identify observational studies, randomised trials, meta-analyses, and systematic reviews.
The estimated risk of cardiac complications in TYAs is compounded by the fact that some patients will also receive mediastinal radiotherapy. In a study of Hodgkin's lymphoma survivors, the actuarial risk of congestive heart failure 25 years after diagnosis was $0.4 \%$ with non-anthracycline chemotherapy without mediastinal radiotherapy, $7.5 \%$ with non-anthracycline chemotherapy and concurrent mediastinal radiotherapy, and $10.7 \%$ with anthracyclines and mediastinal radiotherapy. ${ }^{11}$

\section{Identifying and managing cardiovascular complications}

Regardless of therapy received, offer all TYA cancer survivors lifestyle advice to reduce their risk of cardiovascular disease. These recommendations are summarised in the infographic along with potential symptoms and monitoring advice, and are based on consensus guidelines. Robust evidence showing the effectiveness of prevention strategies does not yet exist. Consider coronary artery disease in all patients who present with chest pain regardless of age if they have a history of chemotherapy. There are no standardised guidelines for ventricular function screening after chemotherapy, but offer this to high risk patients, such as those with a history of anthracyclines or mediastinal radiotherapy. Systolic function can be assessed by echocardiography or a MUGA (multigated acquisition) scan (infographic). ${ }^{4}$ Offer women with any of the risk factors above who become pregnant echocardiography in the second trimester. For the management of left ventricular dysfunction, the best evidence supports ACE inhibitors with $\beta$ blockers. ${ }^{13}{ }^{14}$ A recent, single centre, prospective study of 2625 patients showed that early detection and therapy for anthracycline induced cardiac failure led to substantial recovery of cardiac function. ${ }^{15}$

\section{Fertility}

Loss of fertility can be distressing to cancer survivors. ${ }^{16} 17$ Chemotherapy induced infertility occurs primarily due to dose dependent gonadal toxicity, and alkylating agents such as cyclophosphamide and procarbazine are often implicated. ${ }^{18}$ For example, the MOPP (Mustargen, Oncovin, procarbazine, prednisone) regimen for treating Hodgkin's lymphoma included alkylating agents and led to $20 \%$ amenorrhoea rates in women. ${ }^{19}$
The Childhood Cancer Survivor Study found the relative risk of long term survivors becoming pregnant was 0.81 compared with healthy sibling controls. TYAs comprised $20 \%$ of the study cohort. $^{20}$

The risk to fertility after chemotherapy generally increases with age at treatment. ${ }^{21}{ }^{22}$ In a study of women with Hodgkin's lymphoma, the cumulative risk of premature menopause five years after treatment was higher among those aged 22-28 years than in those aged $14-21$ years $(27.2 \% v 5.6 \%) .{ }^{21}$ Other factors such as concurrent radiotherapy to the gonadal region ${ }^{23}$ also affect risk. Online risk calculators (see www.fertilehope.org/ tool-bar/risk-calculator.cfm) are available to estimate an individual patient's risk. These calculators take into account gender, cancer type, and treatment and can be used by patients and health professionals.

Discuss fertility preservation early when agreeing a management plan and, given that treatment plans may change and that few regimens carry no risk of infertility, offer urgent referral to fertility preservation services for all TYA patients receiving any chemotherapy. ${ }^{24}$ Options for fertility preservation are outlined in table $2 \Downarrow$.

\section{Second malignant neoplasms}

Some $17-19 \%$ of all new primary cancers occur in cancer survivors. ${ }^{35}$ The reason why TYAs are at a greater risk of developing second malignant neoplasms than older survivors is unclear but may be because they receive more intensive drug schedules or because a proportion of patients already have a genetic predisposition to cancer. Data from the Surveillance, Epidemiology, and End Results (SEER) database, which includes details of more than two million cancer survivors, show that the relative risk of second malignant neoplasm decreases with increasing age at primary cancer diagnosis. For instance, for the three age groups $0-17,18-29$, and 50-59 years, the relative risk of second cancer decreased from 6.13 to 2.92 to 1.27 respectively. ${ }^{35}$ The absolute risk varies by type of both primary and second malignant neoplasm-primarily a consequence of the increasing incidence of most cancers with increasing age. ${ }^{36}$

Quantifying the risk of second malignant neoplasm from specific chemotherapy regimens is difficult because TYA cancer survivors may be at risk of second cancers due to genetic or 
environmental factors. ${ }^{37}$ Moreover, many protocols include radiotherapy, which itself is carcinogenic. ${ }^{38}$ However, several drugs have well established associations with a range of solid tumours. ${ }^{37}$ Alkylating agents, topoisomerase II inhibitors, and antimetabolites have been shown to induce therapy related acute myeloid leukaemia and myelodysplastic syndrome. ${ }^{39}$

Currently the only guidelines that exist for screening of second malignant neoplasms are for women at risk of breast cancer having received thoracic radiotherapy. This primarily includes female survivors of Hodgkin's lymphoma and involves yearly mammogram and magnetic resonance imaging (MRI) from eight years after treatment or from age 25 years, whichever occurs later. ${ }^{4}$ In other patients, offer advice and support on lifestyle modifications known to reduce cancer risk including smoking cessation, alcohol use, sun exposure, diet, and exercise. TYAs are recommended to follow cancer screening guidelines applicable to the general population. More intensive screening may be needed for patients with genetic predisposition to cancers.

\section{Neurocognitive effects}

Neurocognitive changes after chemotherapy can affect survivorship. ${ }^{40}$ Antimetabolites and anthracyclines have been implicated. Although the association has long been established in childhood cancers, ${ }^{41}$ emerging evidence shows a similar effect in TYAs. A retrospective study of more than 2500 cancer patients aged 11-21 identified deficiencies in emotional regulation, memory and task efficiency. ${ }^{40}$ These individuals are likely to require additional psychological and social support (see infographic).

\section{Fatigue}

Cancer related fatigue is defined as a "distressing, persistent, subjective sense of physical, emotional, and/or cognitive tiredness or exhaustion related to cancer or cancer treatment that is not proportional to recent activity and interferes with usual functioning., ${ }^{, 42}$ A recent systematic review highlighted that fatigue can be a disabling problem in younger patients with cancer, and that urgent research is needed to identify effective management strategies. ${ }^{43}$ Fatigue affects $17-29 \%$ of all cancer survivors, ${ }^{44}$ and can have a great effect on quality of life and function. ${ }^{44}$ Reversible causes should be explored (see infographic). Short bursts of exertion may be more manageable in these patients, and structured exercise routines, such as a moderate walking exercise programme, have proved to be helpful in improving fatigue and decreasing anxiety. ${ }^{44}$

\section{Psychosocial effects}

It is difficult to untangle which psychosocial effects are a direct side effect of therapy as opposed to the physical and psychological sequelae of cancer diagnosis and treatment during a period of life associated with much change. A recent systematic review on this subject subdivides adolescents and young adults into three groups based on social needs. ${ }^{45}$ The review found that mid-adolescents (15-17 years old) are principally coping with the physical changes of puberty and the formation of a social identity, ${ }^{46}$ whereas emerging adults (18-25 years old) are often in the process of leaving their childhood home, obtaining higher education, and establishing social connections independent from childhood.

\section{Social effects}

A multicentre observational cohort study of TYA cancer survivors in the US found that, although over $72 \%$ of patients previously in full time employment or education had been able to return to full time enrolment at 15-35 months after diagnosis, more than half of this cohort reported difficulties with work or education, including problems with forgetting, keeping up, and paying attention. ${ }^{47}$ In the same study, over $60 \%$ of 498 survey respondents experienced a negative impact of cancer on their financial situation. ${ }^{48}$ Financial issues may become apparent through disruption at work and/or difficulties in obtaining life insurance policies and mortgages.

Maintaining or forming close or sexual relationships with peers and potential life partners can be an issue. A negative body image due to cancer was reported by $61 \%$ of patients in the AYA HOPE study. ${ }^{48}$ This may be associated with specific treatment side effects such as alopecia. ${ }^{46}$ Any cognitive problems related to treatment may also hinder acquisition of social skills and lead to further problems with self esteem. ${ }^{49}$

\section{Psychological effects}

Psychological issues among TYA cancer survivors include stress, anxiety, and depression, which may relate to the disruption of life goals, interpersonal relationships and self image, as well as fear of disease recurrence. ${ }^{49}$ In a recent Australian cross sectional study, $48 \%$ of cancer survivors aged 15-25 years fulfilled the diagnostic criteria for post-traumatic stress disorder (PTSD), ${ }^{50}$ and the risk factors included female sex, less social support, and issues with self image and identity. The parents of these cancer survivors also had a $42 \%$ rate of PTSD, highlighting the need for family based psychological assessments and interventions.

A Canadian registry based study found that TYA cancer survivors were more likely to take antidepressants than healthy controls. ${ }^{51}$ Social isolation is also observed among TYA cancer survivors, who may wish to connect with other TYAs with similar experiences. ${ }^{52}$ However, this may cause negative psychological effects if peers relapse or die.

\section{How can we best manage the psychosocial effects?}

The US National Comprehensive Cancer Network guidelines recommend that TYAs should be involved in decision making from an early age, given age-appropriate information, and specifically asked about their understanding of the information and for permission to share it with parents and others. ${ }^{53}$ Patient empowerment is important in optimising survivorship. TYAs may also wish to access self help groups or online peer support to connect with cancer patients or survivors of a similar age, as well as benefit from advice on how to discuss their diagnosis with others. $^{52}$

US data suggest there is inadequate provision of psychological support to serve the needs of TYA cancer patients, ${ }^{54}$ although corresponding UK data are lacking. The UK National Institute for Health and Care Excellence (NICE) recommends psychosocial needs assessment for patients up to the age of 24 years, and for their families or carers, and to offer appropriate specialist support at "key points" of care including long term follow-up,$^{55}$ as well as early referral to fertility services.

Offer practical support, including referral to occupational health and social services (see infographic), and highlight sources of reliable information. Available resources range from tools for emotional self help, lists of counsellors, and support material for carers and family members, to information on fertility preservation, reasonable adjustments at work, insurance and mortgage issues, and benefits and financial assistance (such as 
free prescriptions for patients requiring treatment for side effects from cancer therapy).

\section{How can we personalise long term care?}

Given that TYA cancer patients may develop a wide array of complex late effects, there is an increasing move among care providers, worldwide, to formulate individualised long term care plans for patients. These care plans would be developed between patients and their multidisciplinary care teams at the end of treatment. These plans can be shared with the patient and primary care provider and would include detail about the treatment regimen, potential late effects, and an individualised plan for monitoring. In the UK this forms part of the recovery package devised by the National Cancer Survivorship Initiative, which includes a standardised holistic needs assessment of each patient after their treatment (including medical, psychological, and financial assessments) and an initial cancer care review carried out at the patient's general practice three to six months after cancer diagnosis. ${ }^{56}$ Similar survivorship initiatives have been launched in other countries, all with the overarching aim of supporting TYA cancer survivors to live a healthy and productive life (supplementary table B).

We thank Jane Robson and Andre Jansen, TYA specialist nurses at Addenbrooke's Hospital, for their help in writing the article; Charlotte Butterworth, a teenage cancer survivor who offered a great insight into how to write the article; and Lily Anderson, a teenage cancer survivor who wrote the patient story.

Contributors: SSA acts as guarantor. SSA planned the article, wrote the initial draft and performed literature review. MAVR helped write the initial draft and devised the tables. HMH planned the article and reviewed the initial draft. TVA planned the article and reviewed all drafts and approved the final article.

Funding: SSA is supported by the Cambridge Cancer Centre. Competing interests: We have read and understood BMJ policy on declaration of interests and declare that we have no competing interests. Patient consent obtained.

Provenance and peer review: Commissioned; externally peer reviewed.

1 Cancer Research UK. Teenagers' and young adults' cancers statistics. http://www cancerresearchuk.org/health-professional/cancer-statistics/teenagers-and-young-adultscancers.

2 National Cancer Institute. A snapshot of adolescent and young adult cancers. http://www. cancer.gov/research/progress/snapshots/adolescent-young-adult.

3 Yang L, Fujimoto J, Qiu D, Sakamoto N. Trends in cancer mortality in Japanese adolescents and young adults aged 15-29 years, 1970-2006. Ann Oncol2009;20:758-66. doi:10.1093/annonc/mdn664 pmid:19150947.

4 Childrens Oncology Group. Long term follow-up guidelines for survivors of childhood, adolescent, and young adult cancers. 2013. http://www.survivorshipguidelines.org/pdf/ LTFUGuidelines 40.pdf.

5 Cancer Research UK. Teenagers' and young adults' cancers statistics: teenagers' and young adults' survival. http://www.cancerresearchuk.org/health-professional/cancerstatistics/teenagers-and-young-adults-cancers\#heading-Two.

6 Trama A, Botta L, Foschi R, et al. EUROCARE-5 Working Group. Survival of European adolescents and young adults diagnosed with cancer in 2000-07: population-based data from EUROCARE-5. Lancet Oncol 2016;17:896-906. doi:10.1016/S1470-2045(16)001625 pmid:27237614.

7 Woodward E, Jessop M, Glaser A, Stark D. Late effects in survivors of teenage and young adult cancer: does age matter?Ann Oncol 2011;22:2561-8. doi:10.1093/annonc/ mdr044 pmid:21427066.

8 Monsuez JJ, Charniot JC, Vignat N, Artigou JY. Cardiac side-effects of cance chemotherapy. Int J Cardiol 2010;144:3-15. doi:10.1016/j.ijcard.2010.03.003 pmid: 20399520.

9 Rugbjerg K, Mellemkjaer L, Boice JD, Køber L, Ewertz M, Olsen JH. Cardiovascular disease in survivors of adolescent and young adult cancer: a Danish cohort study, 1943-2009. J Natl Cancer Inst 2014;106:dju110. doi:10.1093/jnci/dju110 pmid:24848622.

10 Chao $\mathrm{C}, \mathrm{Xu} \mathrm{L}$, Bhatia S, et al. Cardiovascular disease risk profiles in survivors of adolescen and young adult (AYA) cancer: the Kaiser Permanente AYA Cancer Survivors Study. $J$ Clin Oncol 2016;34:1626-33. doi:10.1200/JCO.2015.65.5845 pmid:26951318.

11 Aleman BM, van den Belt-Dusebout AW, De Bruin ML, et al. Late cardiotoxicity after treatment for Hodgkin lymphoma. Blood 2007;109:1878-86. doi:10.1182/blood-2006-07034405 pmid: 17119114.

12 van den Belt-Dusebout AW, Nuver J, de Wit R, et al. Long-term risk of cardiovascular disease in 5-year survivors of testicular cancer. J Clin Oncol 2006;24:467-75. doi:10.1200/ JCO.2005.02.7193 pmid:16421423
13 Cardinale D, Colombo A, Lamantia G, et al. Anthracycline-induced cardiomyopathy: clinical relevance and response to pharmacologic therapy. J Am Coll Cardiol 2010;55:213-20. doi:10.1016/j.jacc.2009.03.095 pmid:20117401.

14 Curigliano G, Cardinale D, Suter T, et al. ESMO Guidelines Working Group. Cardiovascular toxicity induced by chemotherapy, targeted agents and radiotherapy: ESMO clinical practice guidelines. Ann Oncol 2012;23(Suppl 7):vii155-66. doi:10.1093/annonc/ mds293 pmid:22997448.

15 Cardinale D, Colombo A, Bacchiani G, et al. Early detection of anthracycline cardiotoxicity and improvement with heart failure therapy. Circulation 2015;131:1981-8. doi:10.1161/ CIRCULATIONAHA.114.013777 pmid:25948538.

16 Levine J, Canada A, Stern CJ. Fertility preservation in adolescents and young adults with cancer. J Clin Oncol 2010;28:4831-41. doi:10.1200/JCO.2009.22.8312 pmid:20458029.

Benedict C, Shuk E, Ford JS. Fertility issues in adolescent and young adult cancer survivors. J Adolesc Young Adult Oncol2016;5:48-57. doi:10.1089/jayao.2015.0024 pmid: 26812452.

18 Gracia CR, Sammel MD, Freeman E, et al. Impact of cancer therapies on ovarian reserve. Fertil Steril 2012;97:134-40.e1. doi:10.1016/j.fertnstert.2011.10.040 pmid:22137491.

19 Green DM. Fertility and pregnancy outcome after treatment for cancer in childhood or adolescence. Oncologist 1997;2:171-9.pmid:10388048.

20 Green DM, Kawashima T, Stovall M, et al. Fertility of female survivors of childhood cancer: a report from the childhood cancer survivor study. J Clin Oncol 2009;27:2677-85. doi:10. 1200/JCO.2008.20.1541 pmid:19364965.

21 De Bruin ML, Huisbrink J, Hauptmann M, et al. Treatment-related risk factors for premature menopause following Hodgkin lymphoma. Blood 2008;111:101-8. doi:10.1182/blood2007-05-090225 pmid:17890454.

22 Howell SJ, Radford JA, Ryder WD, Shalet SM. Testicular function after cytotoxic chemotherapy: evidence of Leydig cell insufficiency. J Clin Oncol 1999;17:1493-8.pmid: 10334536.

23 Wo JY, Viswanathan AN. Impact of radiotherapy on fertility, pregnancy, and neonatal outcomes in female cancer patients. Int $J$ Radiat Oncol Biol Phys 2009;73:1304-12. doi: 10.1016/.jijrobp.2008.12.016 pmid:19306747.

24 Loren AW, Mangu PB, Beck LN, et al. American Society of Clinical Oncology. Fertility preservation for patients with cancer: American Society of Clinical Oncology clinical practice guideline update. J Clin Oncol 2013;31:2500-10. doi:10.1200/JCO.2013.49. 2678 pmid:23715580

25 Peccatori FA, Azim HA Jr, , Orecchia R, et al. ESMO Guidelines Working Group. Cancer, pregnancy and fertility: ESMO clinical practice guidelines for diagnosis, treatment and follow-up. Ann Oncol 2013;24(Suppl 6):vi160-70. doi:10.1093/annonc/mdt199 pmid: 23813932.

26 Centers for Disease Control and Prevention. Assisted reproductive technology. 2013. ftp: //ftp.cdc.gov/pub/Publications/art/ART-2013-Clinic-Report-Full.pdf.

27 Levine JM, Kelvin JF, Quinn GP, Gracia CR. Infertility in reproductive-age female cancer survivors. Cancer 2015;121:1532-9. doi:10.1002/cncr.29181 pmid:25649243.

28 Practice Committees of American Society for Reproductive Medicine Society for Assisted Reproductive Technology. Mature oocyte cryopreservation: a guideline. Fertil Steril 2013;99:37-43. doi:10.1016/j.fertnstert.2012.09.028 pmid:23083924.

29 Ferrari S, Paffoni A, Filippi F, Busnelli A, Vegetti W, Somigliana E. Sperm cryopreservation and reproductive outcome in male cancer patients: a systematic review. Reprod Biomed Online 2016;33:29-38. doi:10.1016/j.rbmo.2016.04.002 pmid:27156003.

30 Park YS, Lee SH, Song SJ, Jun JH, Koong MK, Seo JT. Influence of motility on the outcome of in vitro fertilization/intracytoplasmic sperm injection with fresh vs. frozen testicular sperm from men with obstructive azoospermia. Fertil Steril 2003;80:526-30. doi: 10.1016/S0015-0282(03)00798-2 pmid:12969692.

31 Hsiao W, Stahl PJ, Osterberg EC, et al. Successful treatment of postchemotherapy azoospermia with microsurgical testicular sperm extraction: the Weill Cornell experience. J Clin Oncol 2011;29:1607-11. doi:10.1200/JCO.2010.33.7808 pmid:21402606.

32 van Wely M, Barbey N, Meissner A, Repping S, Silber SJ. Live birth rates after MESA or TESE in men with obstructive azoospermia: is there a difference? Hum Reprod 2015;30:761-6. doi:10.1093/humrep/dev032 pmid:25740877.

33 Agarwal A, Ong C, Durairajanayagam D. Contemporary and future insights into fertility preservation in male cancer patients. Transl Androl Urol 2014;3:27-40.pmid:26816750.

34 Lambertini M, Del Mastro L, Pescio MC, et al. Cancer and fertility preservation: international recommendations from an expert meeting. BMC Med 2016;14:1.pmid:26728489.

35 Curtis REFD, Ron E, Ries LAG, et al, eds. New malignancies among cancer survivors: SEER Cancer Registries, 1973-2000. National Cancer Institute. 2006.

36 Morton LM, Swerdlow AJ, Schaapveld M, et al. Current knowledge and future research directions in treatment-related second primary malignancies. EJC Suppl 2014;12:5-17. doi:10.1016/j.ejcsup.2014.05.001 pmid:26217162.

37 Travis LB, Demark Wahnefried W, Allan JM, Wood ME, Ng AK. Aetiology, genetics and prevention of secondary neoplasms in adult cancer survivors. Nat Rev Clin Oncol 2013;10:289-301. doi:10.1038/nrclinonc.2013.41 pmid:23529000.

38 Kry SF, Salehpour M, Followill DS, et al. The calculated risk of fatal secondary malignancies from intensity-modulated radiation therapy. Int $J$ Radiat Oncol Biol Phys 2005;62:1195-203. doi:10.1016/j.jijobp.2005.03.053 pmid:15990025.

39 Morton LM, Dores GM, Tucker MA, et al. Evolving risk of therapy-related acute myeloid leukemia following cancer chemotherapy among adults in the United States, 1975-2008. Blood 2013;121:2996-3004. doi:10.1182/blood-2012-08-448068 pmid:23412096.

40 Prasad PK, Hardy KK, Zhang N, et al. Psychosocial and neurocognitive outcomes in adult survivors of adolescent and early young adult cancer: a report from the Childhood Cance Survivor Study. J Clin Oncol 2015;33:2545-52. doi:10.1200/JCO.2014.57.7528 pmid: 26150441.

41 Buizer Al, de Sonneville LM, Veerman AJ. Effects of chemotherapy on neurocognitive function in children with acute lymphoblastic leukemia: a critical review of the literature. Pediatr Blood Cancer 2009;52:447-54. doi:10.1002/pbc.21869 pmid:19061221.

42 Berger AM, Abernethy AP, Atkinson A, et al. Cancer-related fatigue. J Nat/ Compr Canc Netw 2010;8:904-31.pmid:20870636.

43 Spathis A, Booth S, Grove S, Hatcher H, Kuhn I, Barclay S. Teenage and young adult cancer-related fatigue is prevalent, distressing, and neglected: it is time to intervene. A systematic literature review and narrative synthesis. J Adolesc Young Adult Oncol 2015;4:3-17. doi:10.1089/jayao.2014.0023 pmid:25852970

44 Denlinger CS, Ligibel JA, Are M, et al. Survivorship: fatigue, version 1.2014. J Nat/ Compr Canc Netw 2014;12:876-87.pmid:24925198.

45 Warner EL, Kent EE, Trevino KM, Parsons HM, Zebrack BJ, Kirchhoff AC. Social well-being among adolescents and young adults with cancer: A systematic review. Cancer 2016;122:1029-37. doi:10.1002/cncr.29866 pmid:26848713. 


\section{A patient's perspective}

I was diagnosed at 14 years old with stage four Hodgkin's lymphoma and received six rounds of chemotherapy and two weeks of radiotherapy. After six months in remission, I relapsed and was treated with alternating IEP and ABVD chemotherapy, followed by high dose BEAM chemotherapy and a stem cell transplant.

During the course of my treatment, I missed almost two full years of education and was unable to take my GCSEs. I have found it far more difficult to be around people, developing social anxiety and depression, for which I am being treated with medication and cognitive behavioural therapy. Having self confidence and dealing with my frustration is difficult, and I feel that I am a burden to my friends and family. It may help to have services within oncology that help with the emotional side effects while within the service, rather than after it.

I've also struggled with fatigue and have found it hard to work, even part time, and concentrate on my A-levels. Within the service, there is not enough focus around fertility, and I have struggled to cope with being infertile, especially since no measures were taken to help prevent it due to my age. Having osteoporosis has been difficult too. However, the Teenage Cancer Trust has really helped me with my recovery and finding out how to be a person and not a patient, again.

Lily Anderson-TYA cancer survivor

\section{Additional educational resources for patients}

Age-specific

- Teenage Cancer Trust, UK charity (www.teenagecancertrust.org/)—Resources for cancer patients aged 13-24 years, including information on cancer types and treatments; patient stories by tumour type; advice on talking to peers, family, and doctors; information for friends and family; links to support programmes and events

- CLIC Sargent, UK charity (www.clicsargent.org.uk/content/young-people)—Resources for cancer patients aged 16-24 years, including patient stories; Facebook group; online community; information about one-to-one social, emotional, practical, and financial support; free holidays

Further useful links to sources for support for issues including: emotional support, fertility, body image, relationships, finances

- Teens Unite Fighting Cancer, UK charity (http://teensunitefightingcancer.org/)—Resource for cancer patients aged 13-24 years, including patient stories; blog; forum; support with provision of real hair wigs; national events

- JTV Cancer Support, UK project with increasing links to other countries (http://jtvcancersupport.com/)—Online film-based resource for TYA cancer patients providing an extensive collection of videos by patients, their families, and healthcare professionals by cance type, geographical region, topic, or "channel"

General

- Cancer Research UK (www.cancerresearchuk.org/)

- Macmillan Cancer Support, UK charity (www.macmillan.org.uk/)

Comprehensive resources including physical and psychosocial coping and support during and after treatment, including financial support; benefits; grants; mortgages; insurance; travel; fertility preservation; physical and sexual health; emotional help; helpline; online community

\section{Additional educational resources for healthcare professionals}

- National Institute for Health and Care Excellence. Improving outcomes in children and young people with cancer (NICE guideline CSG7). 2005. www.nice.org.uk/guidance/csg7

- Coccia PF, Altman J, Bhatia S, et al. Adolescent and young adult oncology. Clinical practice guidelines in oncology. J Natl Compr Canc Netw 2012;10:1112-50

- Teenage Cancer Trust. Professional resources. 2012. www.teenagecancertrust.org/about-us/what-we-do/professional-leadership/ professional-resources

- National Institute for Health and Care Excellence. Cancer services for children and young people (NICE quality standard QS55). 2014. www.nice.org.uk/guidance/qs55/

- National Cancer Intelligence Network. Cancer in children, teenagers and young adults (links to publications). 2010. www.ncin.org.uk cancer_type and topic_specific_work/cancer_type_specific_work/cancer_in_children_teenagers_and_young_adults/

\section{How patients were involved in the creation of this article}

A Facebook group used by teenage and young adult (TYA) cancer survivors in our region was used to ask if any TYAs would be interested in sharing their views and helping to write the manuscript. One responder has written a patient story while another provided detailed advice on how to focus the article (in particular to focus on psychosocial aspects of survivorship) and reviewed and made suggestions to the final version. These comments specifically ensured that the article highlighted that the list of late effects in the infographic did not include every side effect possible and that the psychological effect of having peers who die during or after treatment is important.

\section{Education into practice}

- Do you offer cardiovascular and cancer prevention advice to teenage and young adult (TYA) cancer survivors to help reduce their risk of late effects such as cardiovascular disease and second cancers?

- Do you know how to refer to local fertility services for TYAs who will receive cytotoxic chemotherapy?

46 Grinyer A. The biographical impact of teenage and adolescent cancer. Chronic IIIn 2007;3:265-77. doi:10.1177/1742395307085335 pmid:18083681

47 Parsons HM, Harlan LC, Lynch CF, et al. Impact of cancer on work and education among adolescent and young adult cancer survivors. J Clin Oncol 2012;30:2393-400. doi:10. 1200/JCO.2011.39.6333 pmid:22614977.

48 Bellizzi KM, Smith A, Schmidt S, et al. Adolescent and Young Adult Health Outcomes and Patient Experience (AYA HOPE) Study Collaborative Group. Positive and negative psychosocial impact of being diagnosed with cancer as an adolescent or young adult. Cancer 2012;118:5155-62. doi:10.1002/cncr.27512 pmid:22415815.

49 Evan EE, Kaufman M, Cook AB, Zeltzer LK. Sexual health and self-esteem in adolescents and young adults with cancer. Cancer 2006;107(Suppl):1672-9. doi:10.1002/cncr. 22101 pmid:16906508.

50 McCarthy MC, McNeil R, Drew S, et al. Psychological distress and posttraumatic stress symptoms in adolescents and young adults with cancer and their parents. J Adolesc Young Adult Oncol 2016;. doi:10.1089/jayao.2016.0015 pmid:27214245. 
Ongoing research studies (a small selection of ongoing trials for teenagers and young adults from Australian, UK, and US trial programmes)

- A study looking at how genes may affect the risk of kidney damage in children or young people who have treatment with ifosfamide (PK 2007 02)

- A pilot randomized controlled trial of the Promoting Resilience in Stress Management (PRISM) intervention for adolescents and young adults with cancer-Study to investigate the effectiveness of the PRISM intervention, which is aimed at promoting self perceived resilience and consequently minimise patient distress

- RITHM, resonance imaging trial for heart biomarkers in adolescent/young (AYA) cancer survivors-Study aimed at identifying asymptomatic patients with cardiovascular disease using MRI

- Mobile health fitness program for adolescent and young adult childhood cancer survivors (TLC FIT)

- Music therapy video development in improving communication, emotional distress, and recovery in adolescents/young adults undergoing treatment for high-risk cancer and their parents

- Risk of fatigue in adolescent and young adult Hodgkin lymphoma patients

- Care after lymphoma (CALy) trial—Phase II pilot randomised controlled trial of a lymphoma nurse-led model of survivorship care

51 Deyell RJ, Lorenzi M, Ma S, et al. Antidepressant use among survivors of childhood, adolescent and young adult cancer: a report of the Childhood, Adolescent and Young Adult Cancer Survivor (CAYACS) Research Program. Pediatr Blood Cancer 2013;60:816-22. doi:10.1002/pbc.24446 pmid:23281214.

52 Kent EE, Parry C, Montoya MJ, Sender LS, Morris RA, Anton-Culver H. "You're too young for this": adolescent and young adults' perspectives on cancer survivorship. J Psychosoc Oncol 2012;30:260-79. doi:10.1080/07347332.2011.644396 pmid:22416959.

53 Coccia PF, Altman J, Bhatia S, et al. Adolescent and young adult oncology. Clinical practice guidelines in oncology. J Nat/ Compr Canc Netw2012;10:1112-50.pmid:22956810.

54 Barnett M, McDonnell G, DeRosa A, et al. Psychosocial outcomes and interventions among cancer survivors diagnosed during adolescence and young adulthood (AYA): a systematic review. J Cancer Surviv2016;. doi:10.1007/s11764-016-0527-6 pmid:26920873.
55 National Institute for Health and Care Excellence. Cancer services for children and young people (NICE quality standard QS55). 2014. https://www.nice.org.uk/guidance/qs55. 56 National Cancer Survivorship Initiative. The recovery package. 2014. http://www.ncsi.org uk/what-we-are-doing/the-recovery-package/.

Published by the BMJ Publishing Group Limited. For permission to use (where not already granted under a licence) please go to http://group.bmj.com/group/rights-licensing/ permissions

This is an Open Access article distributed in accordance with the Creative Commons Attribution Non Commercial (CC BY-NC 3.0) license, which permits others to distribute, remix, adapt, build upon this work non-commercially, and license their derivative works on different terms, provided the original work is properly cited and the use is non-commercial. See: http://creativecommons.org/licenses/by-nc/3.0/. 


\section{Tables}

Table 1/ Top eight cancer types by age group (data from Cancer Research UK)

\begin{tabular}{|c|c|c|c|c|}
\hline \multicolumn{3}{|c|}{$\begin{array}{l}\text { Children (0-14 years old) } \\
\text { (1555 new cases/year) }\end{array}$} & \multicolumn{2}{|c|}{$\begin{array}{l}\text { Teenagers and young adults (15-24 years old) } \\
\text { (2014 new cases/year) }\end{array}$} \\
\hline & Cancer type & $\%$ of total & Cancer type & $\%$ of total \\
\hline 1 & Leukaemia & 30.1 & Lymphomas & 21.0 \\
\hline 2 & Brain, other CNS, and intracranial tumours & 26.5 & Carcinomas & 19.5 \\
\hline 3 & Lymphomas & 10.7 & Germ cell tumours & 15.4 \\
\hline 4 & Soft tissue sarcoma & 6.3 & Brain, other CNS, and intracranial tumours & 13.7 \\
\hline 5 & Sympathetic nervous system tumours & 5.3 & Malignant melanoma & 11.2 \\
\hline 6 & Renal tumours & 5.3 & Leukaemias & 8.8 \\
\hline 7 & Bone sarcoma & 4.2 & Bone tumours & 5.1 \\
\hline 8 & Carcinomas and malignant melanoma & 3.5 & Soft tissue sarcomas & 4.0 \\
\hline
\end{tabular}




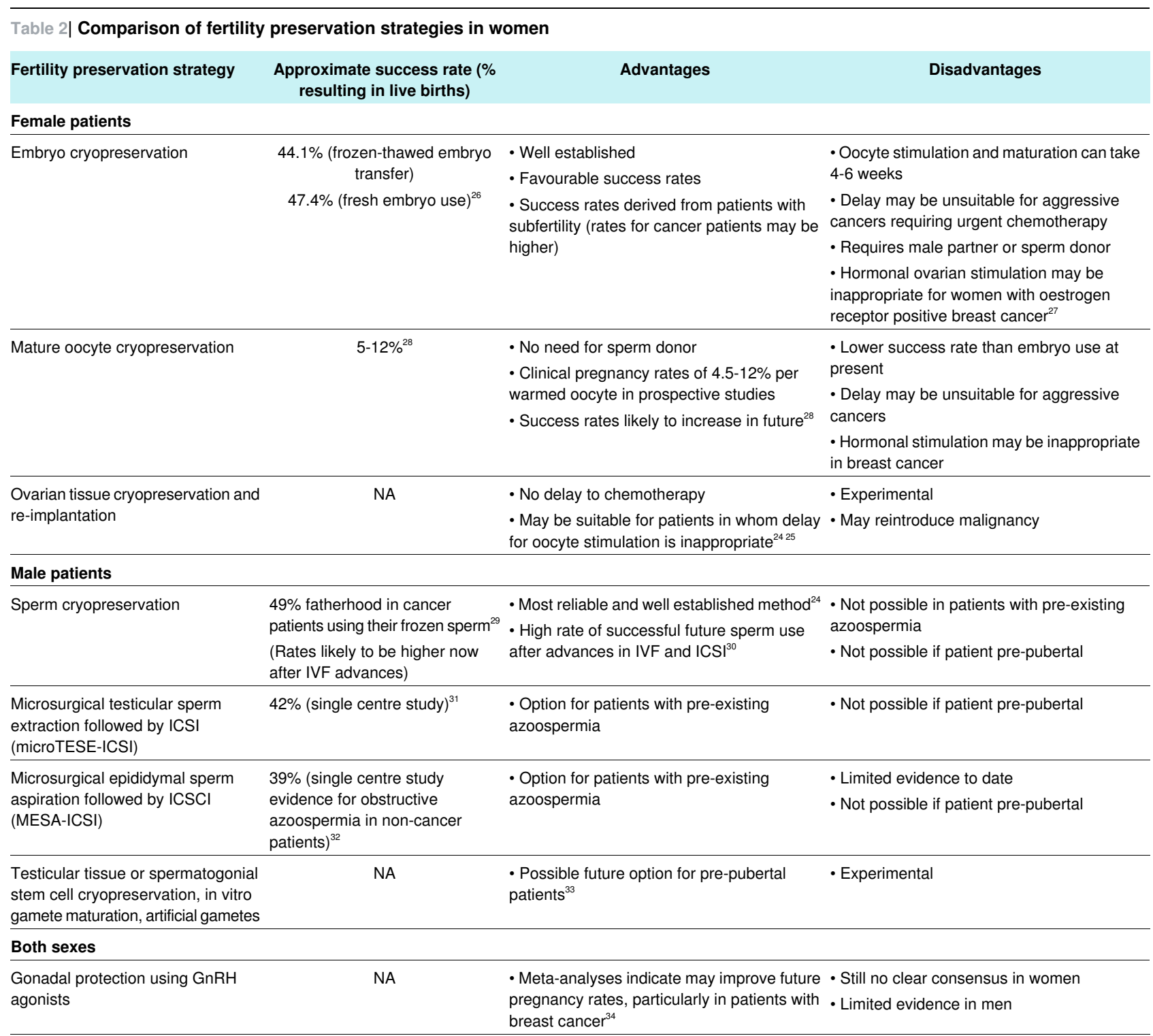

IVF=in vitro fertilisation. ICSI=intracytoplasmic sperm implantation. microTESE=microsurgical sperm retrieval from the testicle. MESA=microsurgical epididymal sperm aspiration. $\mathrm{GnRH}=$ gonadotropin-releasing hormone. 